\title{
Study on the activity of Ni-Co/ZSM-5 catalyst for dehydroaromatization of methane at low temperature
}

\author{
Yi-heng LU* 1,a ${ }^{\text {, Tao Yang }}{ }^{1, b}$, Yu-wei LU ${ }^{2, c}$ \\ ${ }^{1}$ School of Chemical Engineering, Anhui University of Science and Technology, \\ Huainan Anhui, China, 232001 \\ ${ }^{2}$ Laboratoire de Chimie Physique, Universite de Paris Sud, 91405, Orsay Cedex, \\ France . \\ aemail:yhlu2000@163.com, ${ }^{\text {bemail: 931635302@qq.com, }{ }^{c} e m a i l: y u w e i . l u @ u-p s u d . f r ~}$
}

Keywords :methane; dehydro-aromatization; activation; Ni-Co/HZSM-5 catalyst

\begin{abstract}
The Ni-Co/HZSM-5 methane dehydroaromatization (DHA) catalyst was prepared using wet impregnation. The catalysts were characterized by XRD, TEM, TG-DSC, FT-IR and XPS techniques before and after reaction. The results show that the maximum conversion rate of methane DHA at $580^{\circ} \mathrm{C}$ reached $39.8 \%$. The carbon-silicon-oxygen compound after reaction is the main component of coke on surface of the catalyst. The carbon content of the spent catalyst was $490 \%$ higher than that of the fresh sample, indicating a vigorous reaction formed, and there's the possibility of co-catalysis of cobalt and nickel metal in the methane DHA reaction. XPS analysis showed that the catalyst surface coking and deactivation were due to the polymerization of ethylene. The formation of ethylene is believed to be the result of the dehydrogenation of $\mathrm{CH}_{4}$ in the synergistic action of lattice oxygen and cobalt-nickel in the molecular sieve. The decrease of oxygen content on the surface of the catalyst indirectly proves that the oxygen in the catalyst is involved in the methane dehydrogenation reaction.
\end{abstract}

\section{Introduction}

With the continuous reduction of oil resources, methane is a potential substitute for oil due to its transport difficulties and stability[1][2]. The current focus of methane conversion research[3] is the heterogeneous catalytic DHA of methane to produce aromatics, as shown by the reaction (1) or by the production of ethylene through the oxidative coupling of methane, and ethylene oligomerization to produce higher hydrocarbons[4], or methane aromatization [5], using metal catalysts such as Mn, Mo, Zn, Fe and Ga or noble metal Rh, Pd, Ru and supported silica and molecular sieves.

$$
6 \mathrm{CH}_{4} \rightarrow \mathrm{C}_{6} \mathrm{H}_{6}+9 \mathrm{H}_{2}
$$

However, good catalyst should have high activity, especially at low temperatures, high selectivity and stability. Changes in activity loss and selectivity levels caused by deactivation of the catalyst are generally unavoidable. Therefore, for economic reasons, to find ways to reduce catalyst deactivation in theory is very necessary [6]. In the catalytic dehydrogenation of methane, undesired carbonaceous materials are generated and deposited on the catalyst surface. This material plays a major role in the deactivation of the catalyst during the methane dehydrogenation and ethylene (or acetylene) polymerisation reaction. Although a great deal of research has been conducted on the formation and properties of coke deposited on these catalysts, mainly Mo, however, the reaction temperature is generally high (usually $700-1050^{\circ} \mathrm{C}$ ), leading to high energy consumption and equipment materials. So far, the coking problem of methane catalytic aromatization has never been solved. Coking studies for methane DHA catalysts such as cobalt and nickel, especially at low temperatures (e.g. below $600^{\circ} \mathrm{C}$ ) have not been reported.

Taking into account its shape-selective properties and significant active site characteristics, zeolite (e.g.ZSM-5) is mainly used as a catalyst carrier in the refining and petrochemical industry, 
transition metals can activate hydrogen and zeolites to show strong cleavage due to their acidic sites and porous structure properties. Therefore, the Ni, Co and HZSM-5 catalysts for DHA applications were used to study their activity and carbon deposition, they can promote the aromatization or polymerization of ethylene, considering the dehydrogenation of methane to form ethylene or acetylene intermediates [7][8].

In this paper, the Ni-Co/ZSM-5 composite catalyst for methane DHA was prepared by wet impregnation. The surface carbon deposition of the catalyst was characterized by TG-DSC, XPS, TEM and XRD technique. The results show that the maximum conversion rate of methane DHA at $580^{\circ} \mathrm{C}$ reached $39.8 \%$, the carbon-containing silicon-oxygen compound is the main component of coke on catalyst. XPS analysis indicated that the contents of carbon, oxygen and silicon in the spent catalyst were $78.0 \%, 16.1 \%$ and $4.97 \%$, respectively. This demonstrates that the carbon content of spent catalyst was $490 \%$ higher than the fresh catalyst, indicating a vigorous reaction formed, cobalt and nickel metal in the methane DHA reaction there is the possibility of synergistic catalysis.

\section{Experimental}

\section{Chemicals.}

All reagents used were of analytical pure. Nickel nitrate $\mathrm{Ni}\left(\mathrm{NO}_{3}\right)_{2} \cdot 6 \mathrm{H}_{2} \mathrm{O}$ and Cobalt nitrate $\mathrm{Co}\left(\mathrm{NO}_{3}\right)_{2} \cdot 6 \mathrm{H}_{2} \mathrm{O}$ were purchased from the Sinopharm Chemical Reagent Co.(China). ZSM-5 was purchased from the Nankai University Catalyst Factory, Si/Al ratio of 27. Methane, air, nitrogen and hydrogen were 99.9\% purity above and produced by the Nanjing Special Gas Co.(China).

\section{Catalyst preparation.}

$\mathrm{Ni}-\mathrm{Co} / \mathrm{ZSM}-5$ composite catalysts containing 5.0-9.0wt\% Ni and Co were prepared through the wet impregnation of ZSM-5 with $\mathrm{Ni}\left(\mathrm{NO}_{3}\right)_{2} \cdot 6 \mathrm{H}_{2} \mathrm{O}$ and $\mathrm{Co}\left(\mathrm{NO}_{3}\right)_{2} \bullet 6 \mathrm{H}_{2} \mathrm{O}$ and according to literature reported [9].

\section{Determination of catalytic activity.}

The activity of Co-Ni/ZSM-5 zeolite catalyst was measured in a self-made miniature fixed-bed reactor. The reactor was made of quartz glass with inner diameter of $10 \mathrm{~mm}$ and length of $300 \mathrm{~mm}$. The reaction gas pressure was $0.1 \mathrm{MPa}$ and methane purity was $99.9 \%$ gas flow rate of $60 \mathrm{ml} / \mathrm{min}$. Methane gas was bubled into the buffer bottle, the gas was flow through the first $10 \mathrm{~mm}$ diameter $300 \mathrm{~mm}$ quartz glass tube pre-heater, then into the fixed bed diameter of $10 \mathrm{~mm}$ long $300 \mathrm{~mm}$ quartz glass tube, In the middle of the packed fixed bed reactor, $0.702 \mathrm{~g}$ of a $9 \%$ by weight Ni-Co(1:1mol)/ZSM-5 catalyst was added. The fixed bed of the catalyst was first activated by $\mathrm{N}_{2}$ or air at an activation temperature of $400^{\circ} \mathrm{C}$ and then replaced by methane, the reaction temperature was set at $400-580^{\circ} \mathrm{C}$. The reaction product was condensed and cooled, and the mixed gas of the non-condensable brown volatile gas containing the aromatic compound overflowed from the reactor was injected through a 6-way valve and detected on-line using GC2060-TCD. The resulting liquid oil was analyzed by GC 2060-FID. When the temperature is at $580^{\circ} \mathrm{C}$, the reaction is intense, after condensation and liquefaction, the uncondensed tail gas was brown and overflowed with de-ionized water to absorb light brown. After completion of the reaction, the reaction mixture was cooled to room temperature to remove the catalyst.

\section{Apparatus and analysis.}

The XRD patterns of all the samples were recorded on a XRD-6000, Shimadzu X-ray diffractometer using a $\mathrm{Cu} \mathrm{K} \alpha$ radiation source in the $2 \theta$ range of $4^{\circ}-50^{\circ}$. HTEM (High-resolution Transmission Electron Microscope) investigations were carried out using a JEM-2010 (200kV). The gas chromatograph used was GC-2060, a TCD detector used and equipped with a carboxen-1010 capillary packed column, the carrier gas was high purity hydrogen. Fourier transform infrared spectroscopy (FT-IR) analysis was carried out using Thermo Scientific Nicolet 8700, potassium bromide tablets. TG-DSC curves were recorded by DTG-60H and DSC-60 Shimadzu thermal analyzer. The carrier gas was nitrogen or air gas, the heating rate was $10^{\circ} \mathrm{C} / \mathrm{min}$. XPS analysis was an X-ray source of mono-color Al Ka and the Thermo ESCALAB 250 model was used. 


\section{Results and Discussion}

\section{XRD.}

Figure 1(a) shows the XRD patterns of different catalysts. The $2 \theta\left(^{\circ}\right)$ at $8.24,9.16,23.37,23.95$ due to the diffraction peak of ZSM-5 [10], at 37.42 and 43.57 attributed to the diffraction peaks of $\mathrm{Ni}^{2+}$ and $\mathrm{NiO}$, at 31.6, 36.8 and 44.8 attributed to the diffraction peak of $\mathrm{Co}_{3} \mathrm{O}_{4}$, the $2 \theta\left(^{\circ}\right)$ has a weak peak near 37.01 due to the diffraction peak of nickel and cobalt alloy $\mathrm{NiCo}_{2} \mathrm{O}_{4}$. After the reaction, it can be seen that the peak of nickel and cobalt and molecular sieve disappeared,

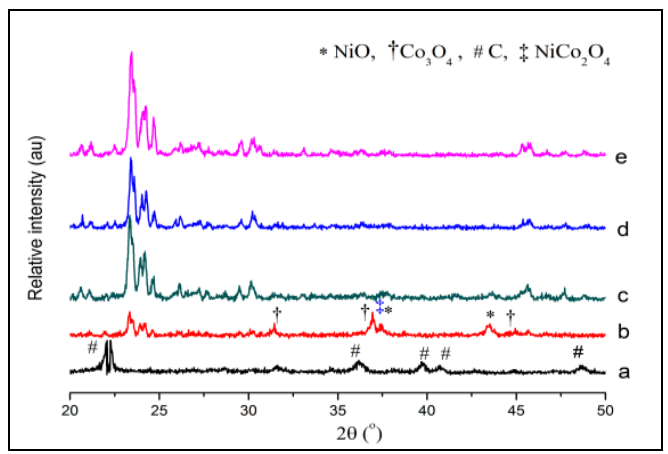

(a)

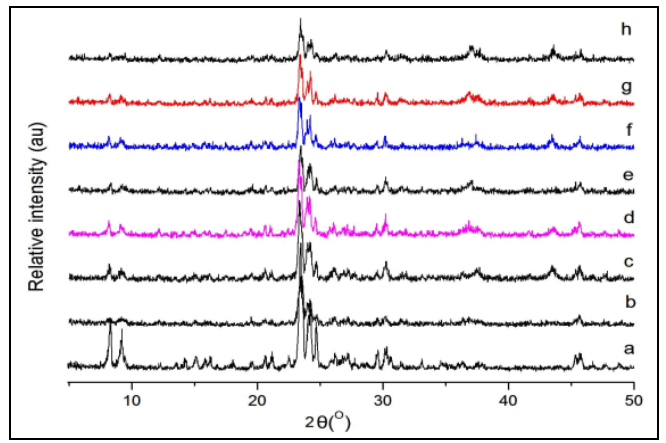

(b)

Fig. 1 XRD patterns of the fresh and spent catalyst

(a): a-9Ni-Co(1:1mol)/ZSM-5(spent); b-9Ni-Co(1:1)/ZSM-5 (fresh) ; c-5Co/ZSM-5; d-5Ni/ZSM-5;e-ZSM-5;c,d and e all are fresh catalysts;

(b): a-ZSM-5;b-5Ni-Co(0.6:1)/ZSM-5;c-5Nio(1:0.6)/ZSM-5; d-5Ni-Co(1:1)/ZSM-5; e-6.2Ni-Co(0.6:1)/ZSM-5;f-6.2Ni-Co(1:0.6)/ZSM-5;g-6.2Ni-Co(1:1)/ZSM-5; h-9Ni-Co(1:1)/ZSM-5; a, b, c, d, e, f and g all are fresh catalysts, at $580^{\circ} \mathrm{C}$.

and the $2 \theta\left({ }^{\circ}\right)$ formed new peaks around 22.4, 36.2, 39.8 and 48.6, which were inferred as the carbide peak on the catalyst surface. Figure 1(b) shows the XRD patterns of the catalysts with different molar ratios. The intensity of characteristic peaks of molecular sieves show a slowly decreasing trend from sample a to $\mathrm{h}$, the $2 \theta\left(^{\circ}\right)$ at 8.0-9.0, 23.0-24.0 and 46.0-47.0 with increasing nickel and cobalt contents. This indicates that nickel and cobalt metal strongly interact with the molecular sieve, while the characteristic peak $2 \theta\left(^{\circ}\right)$ of nickel or cobalt increases in the vicinity of 37.0 and 43.0 .

TG-DSC.

Figure 2 shows the TG-DTG curve of the spent catalyst regenerated in an air atmosphere. When the decomposition temperature is $200,500,600$ and $700^{\circ} \mathrm{C}$, the conversion of catalyst is $4.82,12.18$, 40.51 and $41.43 \%$. It mean that under the action of oxygen in air, the conversion of carbides to $\mathrm{CO}_{2}$, the highest content of the transformed carbon in the catalyst is $41.43 \%$, the content of nickel-cobalt molecular sieve and un-decomposed carbon in the spent catalyst is $58.6 \%$.

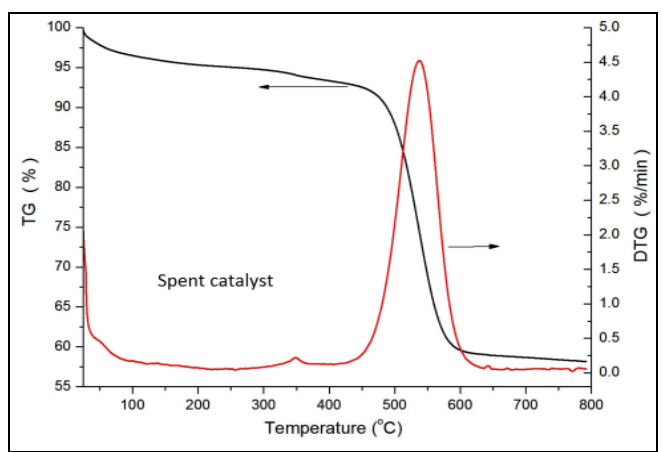

Fig. 2 TG-DTG curves of spent catalyst (Note:9Ni-Co(1:1mol)/ZSM-5, in air )

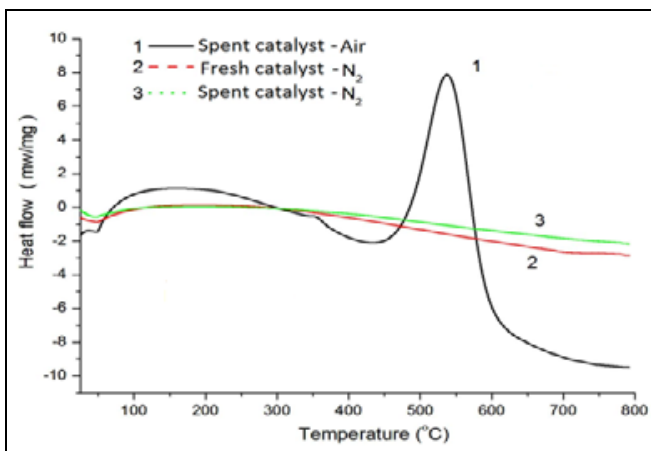

Fig. 3 DSC curves of catalysts in different atmospheres (9Ni-Co(1:1mol)/ZSM-5, 1-spectcatalyst in air;2-fresh catalyst in $\mathrm{N}_{2} 、 3$ - spent catalyst in $\mathrm{N}_{2}$ ) 
From the TG curve, the initial, maximum $\left(\mathrm{T}_{\mathrm{p}}\right)$ and termination decomposition temperature of the catalyst were $252^{\circ} \mathrm{C}, 537.0^{\circ} \mathrm{C}$ and $667^{\circ} \mathrm{C}$ respectively. It showed that the catalyst and its residual carbides were $58.7 \%$ regenerated in the air at $700^{\circ} \mathrm{C}$. The DSC curves of thermal decomposition in different atmospheres are shown in Figure 3. It mean from the curve 1 in the air atmosphere and $450-600^{\circ} \mathrm{C}$, non symmetrical exothermic phenomena are observed, indicating the presence of different overlapping oxidation peaks corresponding to different carbonaceous species on the surface of the spent catalyst. When exothermic peak temperature was $537.4^{\circ} \mathrm{C}$, its maximum mass loss was $25.3 \%$. While the curve 2 and 3 in nitrogen atmosphere, almost two straight lines, there is no endothermic or exothermic peak temperature generation.

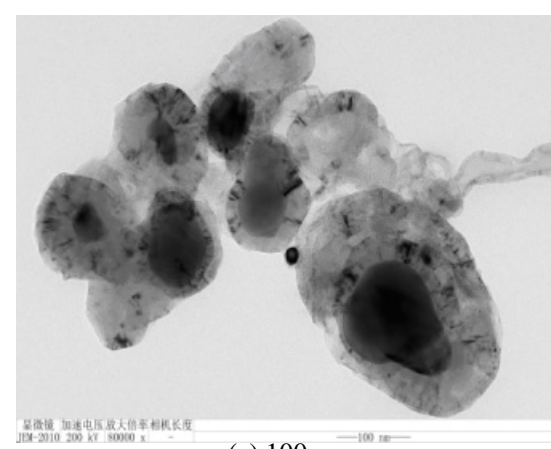

(a) $100 \mathrm{~nm}$

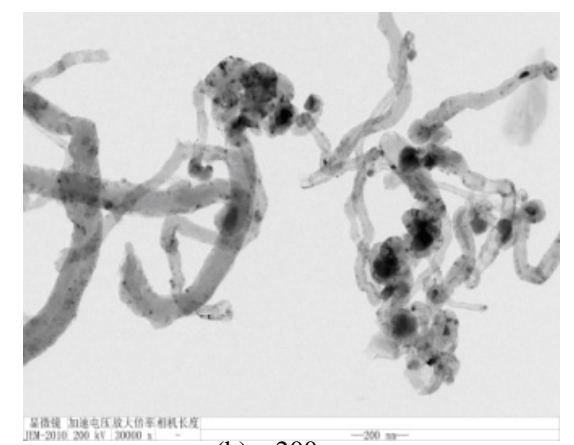

(b) $200 \mathrm{~nm}$

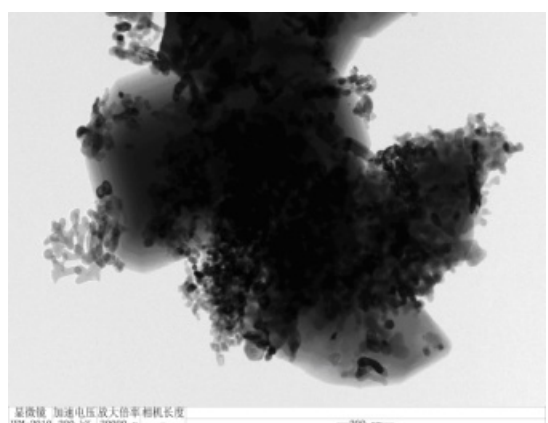

(c) $200 \mathrm{~nm}$

Fig. 4 TEM images of the fresh catalyst and the spent catalyst

( a,b - fresh catalyst; c -spent catalyst; 9Ni-Co/ZSM-5; 9Ni/Co=1:1mol, $0.1 \mathrm{Mpa}, 580^{\circ} \mathrm{C}$ )

\section{HTEM.}

The HTEM images of the fresh and spent catalysts are shown in Figure 4. The Figure 4 (a) and (b) mean the fresh catalyst, the $100-200 \mathrm{~nm}$ is transparent and linear, the characteristics is nickel metal. Figure 4 (c) denote the spent catalyst and 200nm edge is a linear transparent body, most of the black opaque flocculent, is a typical feature of the catalyst surface carbides.

\section{XPS.}

Atom (\%) of the $\mathrm{Ni}, \mathrm{Co}, \mathrm{C}$ and $\mathrm{O}$ for the Ni-Co/ZSM-5 catalysts obtained by XPS analysis showed that after reaction except the C1s increase from 13.07 to $78.02 \%$, the oxygen atoms is reduced from $57.46 \%$ to $16.06 \%$, nickel and cobalt atom\% are reduced from 9.87 and $3.59 \%$ to 0.28 and $0.41 \%$, respectively. The weight (\%) of elements analysis showed that the fresh catalyst compared with the spent one, except the C1 increase from 15.19 to $84.35 \%$, the oxygen wt\% is reduced from $38.25 \%$ to $8.89 \%$. Nickel and cobalt wt\% are reduced from 7.04 and $3.76 \%$ to 0.24 and $0.29 \%$ respectively. Co2p curves showed that two characteristic peaks at $780.9 \mathrm{eV}$ and $796.3 \mathrm{eV}$ attributed to Co2p3/2 and Co2p1/2 respectively for fresh sample. The Co2p3/2 peaks revealed the presence of metallic $\mathrm{Co}_{3} \mathrm{O}_{4}\left(\mathrm{Co}^{3+}\right)$. Whereas the binding energies at $798.0 \mathrm{eV}$ refer to the $\mathrm{Co} 2 \mathrm{p} 1 / 2$ satellites for the spent catalyst. The increase in the binding energy suggested the withdrawal of valence electron charge occurred through oxidation, resulting in higher oxidation state. This result implied a d-electron transfer between $\mathrm{Ni}$ and $\mathrm{Co}$ in the catalyst, resulted in the enrichment of electron on elemental Ni[11]. This result is in accordance with the XRD result, where an additional peak of $\mathrm{NiCo}_{2} \mathrm{O}_{4}$ was detected in the catalyst. Since the characteristic peaks of pure metal oxides were still present, only partial transformation of $\mathrm{NiO}$ and $\mathrm{Co}_{3} \mathrm{O}_{4}$ into $\mathrm{Ni}-\mathrm{Co}$ alloy occurred.

Figure 5(a) shows XPS profiles of coke deposited on the Ni-Co/ZSM-5 catalysts. It reveals nickel, cobalt, oxygen and carbon elements on the coke surface. When placed in air, most of the oxygen was adsorbed into the surface of the spent sample. Ni and Co found on the upper surface showed that coke deposition on the catalyst after DHA at varying temperatures was not uniform. Rather, the coke did not cover the catalyst surface fully. This was also confirmed via TEM imaging. $\mathrm{Ni}$ and Co signal intensities decreased as reaction temperatures increased, and lower $\mathrm{Ni}$ and Co signals were found than the fresh catalyst, indicating that the catalyst surface was gradually covered by coke with increasing temperature. Based on the signal C1s value shown in Figure 5(b), 


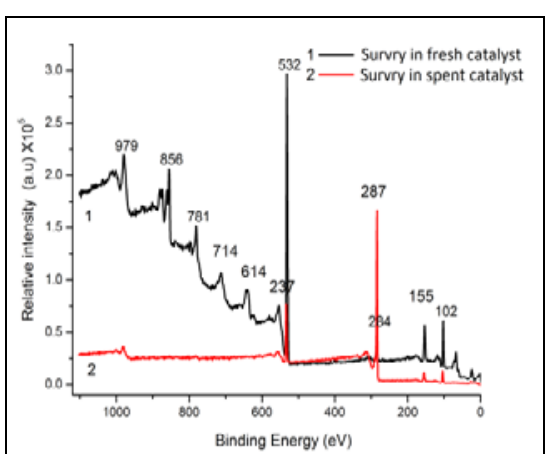

(a) Survry

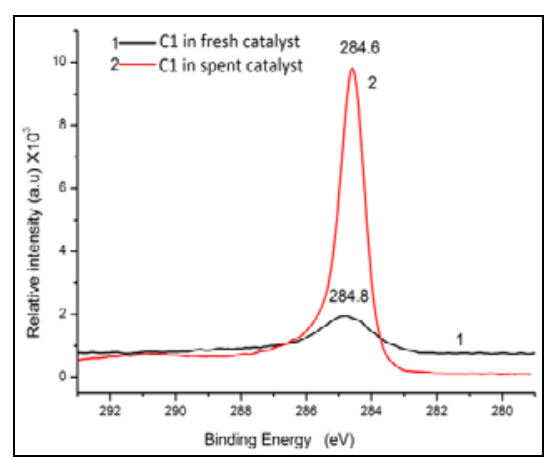

(b) C1 comparison

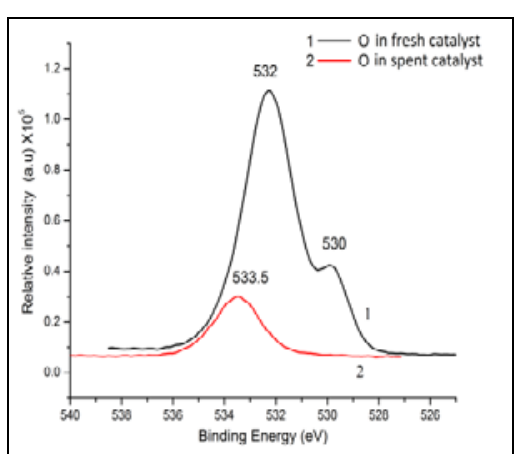

(c) O comparison

Fig. 5 XPS profiles of the Ni-Co/ZSM-5catalyst at $580^{\circ} \mathrm{C}$

Compared with the fresh catalyst, the binding energy of the spent sample decreased obviously from 284.6 to $284.8 \mathrm{eV}$, which was due to the formation of carbides formed by the polymerization of ethylene or acetylene in methane DHA. The carbon content of the spent catalyst was $490 \%$ higher than the fresh catalyst, indicating a vigorous reaction formed at $580^{\circ} \mathrm{C}$, this is presumably the result of synergistic catalysis of nickel and cobalt. The rapid reaction proceeds through methane DHA and polymerization or hydrogen transfer, through the active intermediates ethylene, acetylene or aromatics in the carbide. it also shows the quantitative distribution of coke deposited on the catalysts, as coke forming reactions occur on catalyst surfaces, the degree of coking is controlled by the surface structures.

The O1s spectra for the spent catalyst is shown in Figure 5(c). The O1s binding energy located at $530 \sim 532.0 \mathrm{eV}$ for the fresh catalyst is mostly attributable to adsorbed oxygen, which formed an $\mathrm{O}=\mathrm{C}-\mathrm{O}$ bond. The binding energy $533.5 \mathrm{eV}$ for the spent catalyst is attributable to $\mathrm{O}-\mathrm{C}$ binding in coke. It is also attributed to a shift towards electron charge donation from coke to framework atoms of $\mathrm{Si}$ and $\mathrm{O}$. Comparing the two spectra, the intensity of the component representing $\mathrm{O}-\mathrm{C}$ bonds decreased. The peak of the spent catalyst near 530 and $532 \mathrm{eV}$ almost disappeared, this indicates that the adsorbed oxygen in the pore of the molecular sieve is greatly reduced, oxygen may be replaced by carbon.

\section{FT-IR.}

FT-IR spectra of the Ni-Co/ZSM-5 catalyst exhibited absorption bands at $3154 \sim 3453 \mathrm{~cm}^{-1}$ and $1634 \mathrm{~cm}^{-1}$ attributed to the stretching vibrations of terminal $\mathrm{Si}-\mathrm{OH}$ groups and adsorbed water molecules. While the vibration peak $3453 \mathrm{~cm}^{-1}$ for the molecular sieve within the hydroxyl vibration peak, moved to $3438 \mathrm{~cm}^{-1}$, decreased significantly before and after the intensity of the reaction. This is due to the carbon deposition on the surface of the molecular sieve particles, leading to a reduction in oxygen on the $\mathrm{Si}-\mathrm{OH}$ and $\mathrm{Si}-\mathrm{O}$ groups.

\section{Catalytic reaction.}

The reactant was passed over the activated catalyst and the products were analyzed using online gas chromatograph. The methane conversion was calculated according to the following formula (2):

$$
X_{\mathrm{CH} 4}=\frac{\left[\mathrm{CH}_{4}\right]_{\text {in }}-\left[\mathrm{CH}_{4}\right]_{\text {out }}}{\left[\mathrm{CH}_{4}\right]_{\text {in }}} \times 100 \%
$$

where $\left[\mathrm{CH}_{4}\right]_{\text {in }}$ and $\left[\mathrm{CH}_{4}\right]_{\text {out }}$ are the molar concentration of methane in the feed and effluent. The reaction product consists of three parts:(1) the uncondensed gas phase is methane, ethylene and volatile aromatics analyzed by the GC2060-TCD; (2) the condensed liquid oil is aromatics analyzed by GC2060-FID; (3) the catalyst is coking carbide. The conversion of methane DHA for the Ni-Co /ZSM-5 catalyst was shown that as the temperature raised to $580^{\circ} \mathrm{C}$, the conversion rate of methane increased to $39.8 \%$, then decreased sharply, at this point may be due to serious carbon deposition catalyst pores, then flow gas resistance increases, resulting in lower reaction rate may be caused by the radical initiation of the methyl radical chain, resulting in ethylene polymerization and aromatics generation. 


\section{Conclusion}

The study on the activity of the Ni-Co/ZSM-5 catalyst for methane DHA showed that the maximum conversion rate of methane at $580^{\circ} \mathrm{Creached} 39.8 \%$. The carbon containing siliconoxygen compound is the main component of coke on catalyst. The carbon content was $490 \%$ higher than before the reaction, indicating a vigorous reaction formed. This indicates that there is the possibility of synergistic catalysis for cobalt and nickel metal. XPS analysis indicated that the catalyst surface coking was due to the polymerization of ethylene. The formation of ethylene is presumed to be the result of the dehydrogenation of $\mathrm{CH}_{4}$ under the synergetic action of lattice oxygen of the molecular sieve and cobalt-nickel. The decrease of oxygen content after coking on the catalyst surface indirectly proves that the oxygen in catalyst is involved in the methane DHA.

\section{Acknowledgment}

This research was financially supported by the following grants: (1) Anhui International Science and Technology Cooperation Program (1503062027), (2) Anhui University of Science and Technology Graduate Education Fund (2015-2016).

\section{References}

[1] W.Taifan, J.Baltrusaitis. $\mathrm{CH}_{4}$ conversion to value added products: Potential, limitations and extensions of a single step heterogeneous catalysis[J]. Applied Catalysis B: Environmental, 2016, 198: 525-547

[2] PVL.Reddy, KH.Kim, H.Song. Emerging green chemical technologies for the conversion of $\mathrm{CH}_{4}$ to value added products[J]. Renewable and Sustainable Energy Reviews, 2013, 24:578-585

[3] AI.Olivos-Suarez, A.Szécsényi, EJM.Hensen, J.Ruiz-Martinez, EA.Pidko, J.Gascon. Strategies for the direct catalytic valorization of methane using heterogeneous catalysis: challenges and opportunities[J]. ACS Catalysis, 2016, 6: 2965-2981

[4] H. Coqueblin, A.Richard, D.Uzio, L.Pinard, Y.Pouilloux, F.Epron. Effect of the metal promoter on the performances of H-ZSM5 in ethylene aromatization[J]. Catalysis Today, In press, corrected proof- note to users, Aug. 2016, doi: 10.1016/j.cattod.2016.08.006

[5] XG. Guo, GZ.Fang, G.Li, H. Ma, et al. Direct, nonoxidative conversion of methane to ethylene, aromatics and hydrogen[J] Science, 2014, 344: 616-618

[6] MN. Uddin, WMAW.Daud, HF.Abbas. Kinetics and deactivation mechanisms of the thermal decomposition of methane in hydrogen and carbon nanofiber co-production over Ni-supported Y zeolite-based catalysts[J]. Energy Conversion and Management, 2014, 87: 796-809

[7] C.Karakaya, RJ.Kee. Progress in the direct catalytic conversion of methane to fuels and chemicals[J]. Progress in Energy and Combustion Science, 2016, 55: 60-97

[8] R.Horn, R.Schlogl. Methane Activation by Heterogeneous Catalysis[J]. Catalysis Letters. 2015, 145: 23-39

[9] J. Estephane, S. Aouad, S. Hany, et al. $\mathrm{CO}_{2}$ reforming of methane over Ni-Co/ZSM-5 catalysts. aging and carbon deposition study[J].International Journal of Hydrogen Energy,2015,40:9201-9208 [10] H.Ay, D.Üner. Dry reforming of methane over $\mathrm{CeO}_{2}$ supported $\mathrm{Ni}$, Co and $\mathrm{Ni}-\mathrm{Co}$ catalysts [J]. Applied Catalysis B: Environmental. 2015, 179:128-138

[11] Y.Yu, Q.Jin, Y. Wang, X.Guo. Synthesis of natural gas from CO methanation over SiC supported Ni-Co bimetallic catalysts[J]. Catalysis Communications. 2013, 31:5-10 